\title{
Harvesting the rubber tree once in four days; a solution to current issues in the rubber industry in Sri Lanka
}

\author{
V H L Rodrigo*, K V V S Kudaligama*, K M E P Fernando** and \\ P A J Yapa** \\ * Rubber Research Institute of Sri Lanka, Dartonfield, Agalawatta, Sri Lanka \\ ** University of Sri Jayawardenapura, Nugegoda, Sri Lanka
}

Received 15 November 2011; Accepted 30 December 2011

\begin{abstract}
Despite it's importance, latex harvesting in rubber plantations poses significant problems demanding high level of skilled workers and cost of production. Low frequency harvesting (LFH) instead of traditional half spiral-once in two days system ( $S / 2$ d2), appears to be a practical solution to arrest these issues. Reduction of harvesting frequency has been limited only up to once in three days $(S / 2 d 3)$ for Sri Lankan genotypes. Therefore based on some preliminary investigations, the present study was aimed at developing a suitable protocol for harvesting the rubber tree once in four days with the half spiral cut length ( $S / 2 d 4)$. In addition to the small scale genotypic comparison, the study comprised the commercial testing of S/2 d4 system. The overall yield given by the traditional $S / 2 d 2$ was used as the standard for the comparison and the stimulation protocol of this system was adjusted to obtain similar yields.

The yield given by $S / 2 d 4$ under the stimulation protocol, applying 3.3\% Ethephon (ET) once a month was comparable with that of the traditional $S / 2 d 2$ only in the wet areas of the country. Latex physiological parameters assured the sustainability of the stimulation protocol in all genotypes tested except in RRIC 102. At commercial level, $S / 2 d 4$ system has resulted in $19 \%$ reduction in the cost of production, $22 \%$ increase in overall profitability, $26 \%$ increase in harvesters' income and $50 \%$ reduction in worker requirement in harvesting. Potential long-term impact of this system on latex yields and socio-economic sustainability, awareness programmes and limitations of LFH in dry climates are also discussed.
\end{abstract}

Key words: bark consumption, COP, latex harvesting, latex physiology, low frequency, worker shortage 


\section{Introduction}

Harvesting latex from the rubber tree (Hevea brasiliensis) is considered to be the most costly operation contributing to ca. 1/3 of the total cost of production, particularly in commercial plantations. It requires greater level of skill and this together with poor wage structure has led to the shortage of skilled harvesters (Rodrigo et al., 2004).The problem is aggravated with unfavourable weather conditions, interrupted working days, poor ground conditions (eg. weeds), improper infrastructure facilities (eg. long distance head carrying of latex) and lack of training programmes. As a result large extents of productive rubber clearings have been left without being tapped regularly or tapped by unskilled harvesters, damaging the long-term yield potential of the rubber trees. Studies show that $c a .12 \%$ of the rubber extent is untapped regularly and $c a$. $37 \%$ of harvesters employed in the plantation sector are not skilled (Rodrigo et al., 2004).

In harvesting, rubber tree is generally tapped along the half of the circumference of the trunk $(\mathrm{S} / 2)$ at the frequency of once in two days (d2); hence each harvester is given two blocks of trees (tapping blocks). Removal of skill factor has not been successful and not cost effective in instances where it has been tried (eg. mechanized tapping), hence international focus has been made to improve the efficiency in the usage of skilled harvesters through the introduction of low frequency harvesting systems (LFH). Time gap between two tappings are extended by few more days in LFH, therefore each harvester can be allocated to a greater number of tapping blocks resulting in reduced harvester requirement when compared with the traditional tapping system. In order to compensate the yield loss due to less number of tapping days per tree, yield stimulants are applied thereby yield per tree per tapping can be increased. This result in enhanced daily intake per harvester and therefore, their wages can be increased. Furthermore, overall increase in harvesters' productivity results in reduction of cost of production. Less bark consumption in LFH results in increased economic life of the tree providing an additional benefit to the growers.

Experiments on LFH systems in Sri Lanka have been basically with $\mathrm{d} 3$ systems, i.e. half spiral tapping once in three days with stimulation $(\mathrm{S} / 2 \mathrm{~d} 3+$ ET). First recommendation on this system was issued in 1994 (Nugawela, 2001) bringing down the harvester requirement by $1 / 3$ and cost of tapping by ca. $20 \%$ (Nugawela et al., 2000). Due publicity to this system had not been given resulting in that only a few managers in the plantation sector were aware of the protocol and the importance of d3 tapping (Rodrigo et al., 2004).

Researches in India were also in favour of LFH systems (Karunaichamy et al., 2001) and they recommend tapping a tree once in four days and six days (Vijayakumar et al., 2004). LFH 
V H L Rodrigo et al.

systems of $\mathrm{d} 3, \mathrm{~d} 4, \mathrm{~d} 5$, $\mathrm{d} 6$ (i.e. tapping a tree once in 3 to 6 days) are practised in China (Xuehua et al., 2004). Response of different genotypes (rubber clones) to LFH systems differs (Vijayakumar et al., 2004) and would depend on the climatic conditions. Clones developed in Sri Lanka are grown in most of other rubber growing countries, but have not been tested for extended LFH systems. Initial studies of the Rubber Research Institute of Sri Lanka on the use of extended LFH systems under Sri Lankan conditions have been promising (Rodrigo, 2009). The present study was aimed to asses the effectiveness of LFH $(\mathrm{S} / 2 \mathrm{~d} 4)$ system and to develop a suitable protocol for its application in plantations.

\section{Materials and Methods}

This study comprised two sets of experiments, i.e. further testing of the stimulation protocols identified before (Rodrigo, 2009) for $S / 2 d 4$ and $S / 2 d 6$ systems to assess the long term effects and the commercial level testing of most prominent extended LFH system (i.e. $\mathrm{S} / 2 \mathrm{~d} 4$ ) for the refinement of the technologies and to assess the financial viability.

The study began in 2008 with three important Sri Lankan clones, i.e. RRIC 100, RRIC 102 and RRIC 121, planted during 1989-1990 in Dartonfield estate of the Rubber Research Institute of Sri Lanka (RRISL). All were tapped on BI1 panel except RRIC 121 of which few trees were tapped on BI-2 during the last stage of the experiment. In parallel, another three mature fields were selected from the RRISL substation, Kuruwita (clone RRIC 100) and Udapola estate, Deraniyagala (clone RRIC 102) from the Wet zone and Notinghill estate, Mawathagama (RRIC 121) from the Intermediate zone. Harvesting systems were based on half spiral cut length $(S / 2)$ and $d 2, d 3, d 4$ and d6 tapping frequencies were imposed with different stimulation protocols. However, in Nottinghill estate, $\mathrm{S} / 2$ d6 system was not imposed due to insufficient number of trees. Whilst no stimulation was done in $S / 2$ $\mathrm{d} 2$, Ethephon was applied in $\mathrm{S} / 2 \mathrm{~d} 3, \mathrm{~S} / 2$ $\mathrm{d} 4$ and $\mathrm{S} / 2 \mathrm{~d} 6$ tapping frequencies with $2.5 \%$ concentration 5 times per year as every two months except defoliation period (ET2.5\% 5/y), 2.5\% concentration 9 times per year as monthly applications except defoliation period (ET2.5\% 9/y) and 5\% concentration 12 times per year as monthly applications (ET5\% 12/y), respectively. Stimulation protocols of $\mathrm{S} / 2 \mathrm{~d} 4$ and $\mathrm{S} / 2 \mathrm{~d} 6$ were adjusted after one year and nine months in order to achieve the overall yield given by the traditional $\mathrm{S} / 2$ d2 system (Table 1). Each tapping system was applied on 25 tree plots with three replicates in each site. In all sites, the trees were rainguarded to overcome rain interference on harvesting.

In all sites, latex yield records were gathered in each tapping whilst other yield related parameters of the rubber tree (e.g. girth of trees, length of taping cut and bark thickness) were assessed at 
six month intervals. Whilst measuring tape was used for girth and length of tapping cut, bark thickness was assessed with a standard bark gauge. Trees affected with tapping panel dryness and also, bark consumption under each tapping system were assessed at six month intervals. In order to assess latex physiological parameters; i.e. $\mathrm{pH}$, sucrose, thiol and inorganic phosphorous, latex samples were collected on two occasions and in an ice bath within 5-30 minutes after tapping and analyses were made using spectrophotometric methods (Scott \& Melvin, 1953; Taussky \& Shorr, 1953; Boyne \& Ellman; 1972). In addition, laboratory analyses were made for percentage dry rubber content (\%DRC), total solids content (\%TSC) and acetone extractable non rubber (\%AENR) in latex (Anon, 1970; Anon, 1984).

\section{Commercial testing;}

In order to save the time, commercial level testing of the most prominent LFH system, i.e. $\mathrm{S} / 2 \mathrm{~d} 4$, began soon after the initial identification of suitable stimulation protocols. This was confined initially to two locations representing both Wet and Intermediate zones of the rubber growing areas. The former was located in Udapola estate, Daraniyagala and the latter was in Notinghill estate, Mawathagama (mean annual rainfall is not less than $3300 \mathrm{~mm}$ and $1400 \mathrm{~mm}$, respectively). Clone RRIC 121 was in both sites and in Udapola, a newly opened field for tapping was used for the study (planted in 2001). In Notinghill, trees had been planted in 1997 and tapped on BO-I panel with the $S / 2 d 3$ harvesting system. Adhering to commercial practices, four tapping blocks (each having ca. 300 trees) were assigned to a harvester for $\mathrm{S} / 2 \mathrm{~d} 4$ tapping along with three blocks to $\mathrm{S} / 2$ d3 tapping for comparison in Notinghill. However in Udapola, only two tapping blocks were assigned to $\mathrm{S} / 2$ $\mathrm{d} 4$ and one to $\mathrm{S} / 2 \mathrm{~d} 3$ due to the limited availability of suitable tapping blocks. Further, two blocks for traditional S/2 d2 tapping was assigned to another harvester only in the field of Notinghill estate.

Table 1. Stimulation protocols of different low frequency harvesting systems together with the time periods tested

\begin{tabular}{lll}
\hline Harvesting system & Stimulation protocols tested & \\
\hline $\mathrm{S} / 2 \mathrm{~d} 2$ & - & \\
\hline $\mathrm{S} / 2 \mathrm{~d} 3$ & $\begin{array}{l}2.5 \% \text { ET } 5 \text { rounds per year } \\
\text { (Jan08-Sep10) }\end{array}$ \\
\hline $\mathrm{S} / 2 \mathrm{~d} 4$ & $\begin{array}{l}2.5 \% \text { ET monthly except wintering } \\
\text { 9 rounds per year (Jan08-Sep09) }\end{array}$ & $\begin{array}{l}3.3 \% \text { ET monthly 12 rounds } \\
\text { pear }(\text { Oct09-Dec10) }\end{array}$ \\
\hline $\mathrm{S} / 2 \mathrm{~d} 6$ & $\begin{array}{l}5 \% \text { ET monthly 12 rounds per year } \\
\text { (Jan08-Sep09) }\end{array}$ & $\begin{array}{l}5 \% \text { ET after every three } \\
\text { tappings 20 rounds per } \\
\end{array}$ \\
& year (Oct09-Sep10) \\
\hline \hline
\end{tabular}


V H L Rodrigo et al.

In addition, another set of commercial testing began in Kuruwita substation of RRISL in 2010 (clone RRIC 100) with three tapping blocks allocated to S/2 d4 and two blocks to $S / 2 \mathrm{~d} 2$. Yields were assessed for six months.

Whilst no stimulation was done in $\mathrm{S} / 2$ $\mathrm{d} 2$, the standard protocol for Ethephon stimulation was applied in $\mathrm{S} / 2 \mathrm{~d} 3$ system (Nugawela, 2001). Ethephon application in $\mathrm{S} / 2 \mathrm{~d} 4$ was changed along with other experimental plots from $2.5 \%$ concentration 9 times per year (ET2.5\% 9/y) and 3.3\% concentration 12 times per year as monthly applications (ET3.3\% 12/y) (Table 1). However in Udapola estate, no change in the stimulation protocol of $\mathrm{S} / 2 \mathrm{~d} 4$ was required as it was sufficient to provide the similar yields given by $S / 2$ d3 system.

For an additional investigation on the appropriate Ethephon concentration for the S/2 d4 LFH system, a small scale short-term experiment was conducted in Kuruwita Substation and Notinghill estate, Mawathagama representing both Wet and Intermediate zones, respectively. A series of Ethephon concentrations was applied on trees tapped on $\mathrm{S} / 2 \mathrm{~d} 4$ system (five trees for each concentration). Ethephon was in four concentrations $(2 \%, 3 \%, 4 \%$ \& $5 \%$ ) and applied without disturbing the usual stimulation frequency. Five trees were also tapped with $\mathrm{S} / 2 \mathrm{~d} 2$ as the control. Latex yield of the trees was recorded between two Ethephon applications and yield per tree per year was estimated with the knowledge on the mean yield per tree per tapping and the standard tapping days per year (i.e. 180 for $\mathrm{S} / 2 \mathrm{~d} 2$ and 90 for $\mathrm{S} / 2 \mathrm{~d} 4$ ).

\section{Data analyses}

From daily records on latex yields, mean values for yield per tree per year (YPT), yield per hectare per annum (YPH), daily intake per harvester (IPH) and percentage dry rubber content in latex (\%DRC) were derived for each treatment plot. Similarly, growth data at tree level were processed into mean values in each treatment plot. ANOVA was performed for each parameter together with the mean separation (Dunnett's Test and Duncans's Multiple Range Test) using the statistical package the SAS system 9.2. Values of the traditional $\mathrm{S} / 2 \mathrm{~d} 2$ were the standards in evaluation. In order to avoid the effects of site specific variations in relation to differences in growth stages and soil conditions, statistical analyses were performed separately for each site. Financial viability of $S / 2 \mathrm{~d} 4$ harvesting system was assessed at commercial level with the knowledge on both cost and benefit components for a given period of one year. No consideration to the long-term effects such as extending the lifespan of rubber trees due to reduced bark consumption in LFH, was given in this analysis. Tapping cost was based on the current daily wage of workers (Rs.572/=) plus the payment made on additional latex brought in (Rs.15 per $\mathrm{kg}$ above $7 \mathrm{~kg}$ norm) and Ethephon application cost [chemical cost, Rs.5,425/= per 5 litre plus the 
labour cost of Rs.380/= per tapping block per application]. Overall overhead costs (general charges) was considered to remain unchanged in an estate hence at hectare level (Rs.222,585/= per hectare).

\section{Results}

There was a change in the stimulation protocols of new low frequency harvesting ( $\mathrm{LFH})$ systems in the attempt of achieving the standard yield, i.e. the level given by the $\mathrm{S} / 2 \mathrm{~d} 2$ system. With given importance, only the yield parameters at the last stage are given. There was no significant difference in latex yields in terms of the amount of rubber harvested per tree per year (YPT) among different harvesting systems except in Udapola and Notinghill estates (Fig. 1). In RRIC 102 of Udapola estate, YPT of S/2 d3 and $\mathrm{S} / 2$ d6 systems was significantly less than that of $S / 2 d 2$. Similarly, YPT of both $\mathrm{S} / 2 \mathrm{~d} 3$ and $\mathrm{S} / 2 \mathrm{~d} 4$ was significantly less in Notinghill estate. Though not significant mostly due to the level of variation within the site, YPT was considerably less in d6 except in RRIC 121 of Dartonfield estate. On average for all sites, YPT was 5.26, 4.99, 4.80 and $3.92 \mathrm{~kg}$ in $\mathrm{S} / 2 \mathrm{~d} / 2, \mathrm{~S} / 2 \mathrm{~d} 3, \mathrm{~S} / 2 \mathrm{~d} 4$ and $\mathrm{S} / 2$ d6 systems, respectively.

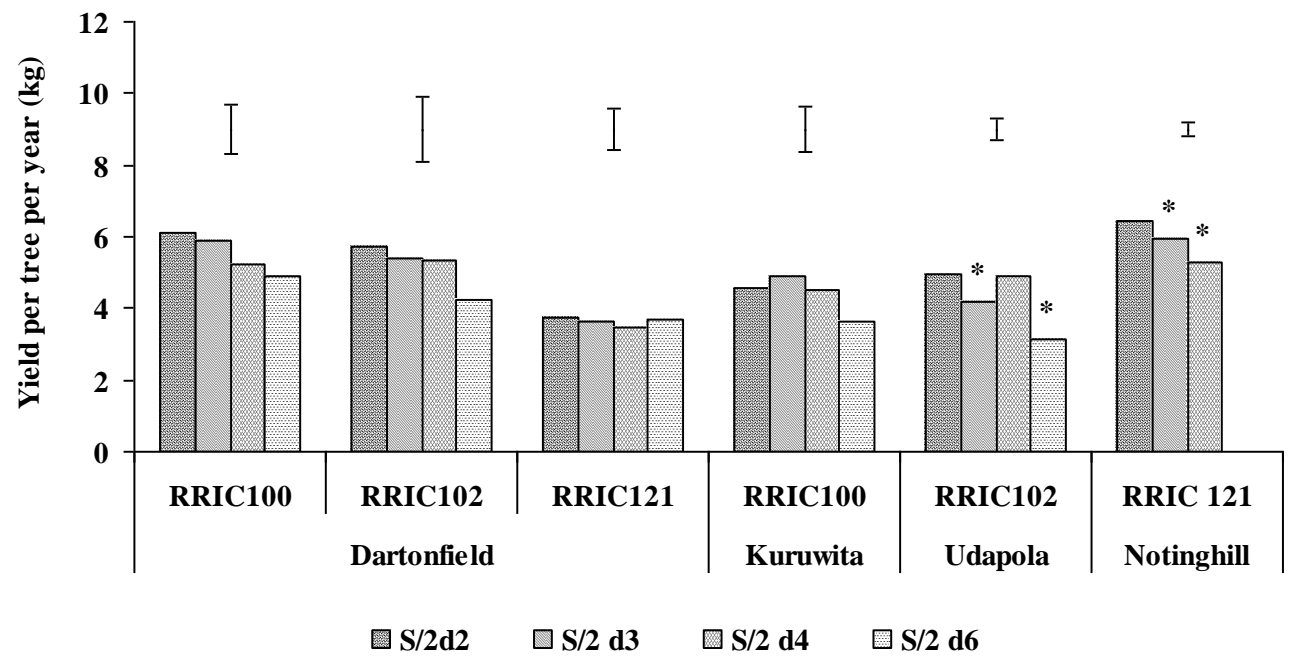

Fig.1. Amount of rubber harvested per tree per year (YPT) in different Low Frequency Harvesting (LFH) systems. Error bars indicate the minimum significant difference for the location and the symbol ' $*$ ' is to show the significant difference $(p<0.05)$ of the respective mean value from the mean of $\mathrm{S} / 2 \mathrm{~d} 2$ system 


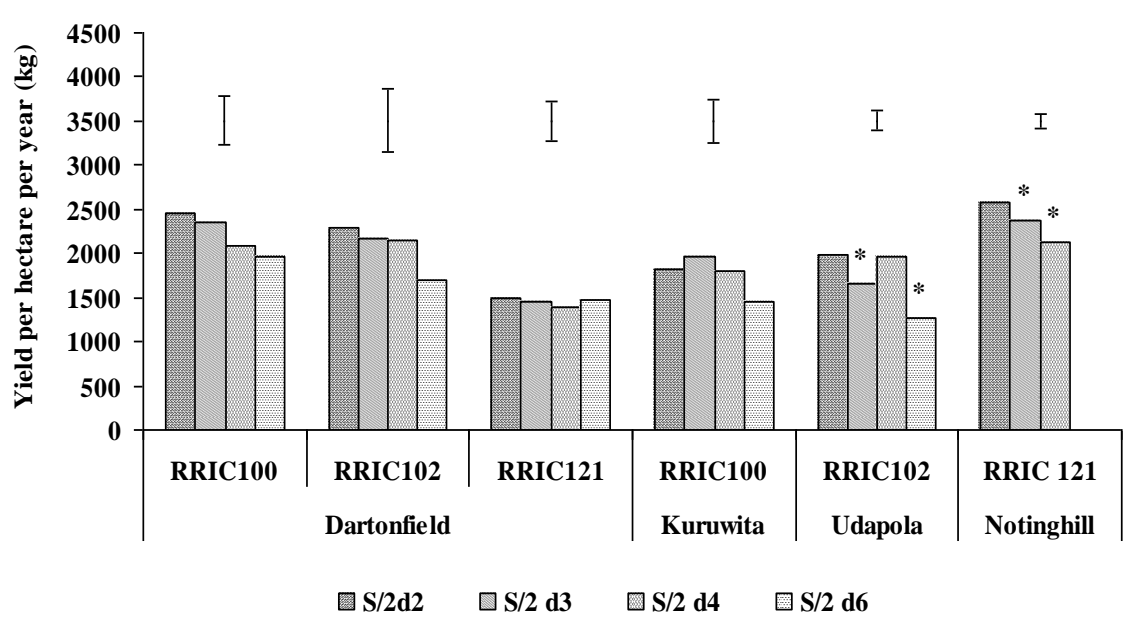

Fig. 2. Yield per hectare per year (YPH) in different Low Frequency Harvesting (LFH) systems. Error bars indicate the minimum significant difference for the location and the symbol ' $*$ ' is to show the significant difference $(p<0.05)$ of the respective mean value from the mean of $\mathrm{S} / 2 \mathrm{~d} 2$ system

Yield per hectare per year (YPH) also followed the pattern of YPT (Fig. 2). With that, YPH was significantly less in $\mathrm{S} / 2 \mathrm{~d} 3$ and $\mathrm{S} / 2 \mathrm{~d} 6$ in Udapola estate and $\mathrm{S} / 2 \mathrm{~d} 3$ and $\mathrm{S} / 2 \mathrm{~d} 4$ in Notinghill estate and also, low values in $\mathrm{S} / 2 \mathrm{~d} 6$ were prominent in all sites except in RRIC 121. However, for any site and any harvesting system, YPH was above $1000 \mathrm{~kg}$. In general, yield per unit length of tapping cut (YPCL) also showed a similar behaviour following the pattern of YPT and YPH (Fig. 3). Nevertheless, YPCL of Notinghill in $\mathrm{S} / 2 \mathrm{~d} 4$ was slightly higher than that of
$\mathrm{S} / 2$ d3. Overall mean YPCL for any system was 112.10 grams per $\mathrm{cm}$ per annum.

Percentage dry rubber content in latex (\%DRC) of any LFH system showed no significant difference from that of $S / 2$ d2 in Dartonfield and Notinghill (Fig. 4). In Kuruwita, \%DRC in all LFH systems was greater than that of $\mathrm{S} / 2 \mathrm{~d} 2$. However, in Udapola, \%DRC in S/2 d4 was higher whilst \%DRC in $\mathrm{S} / 2 \mathrm{~d} 6$ was less than that in $S / 2 d 2$. In general, values recorded for \%DRC were above $30 \%$. 


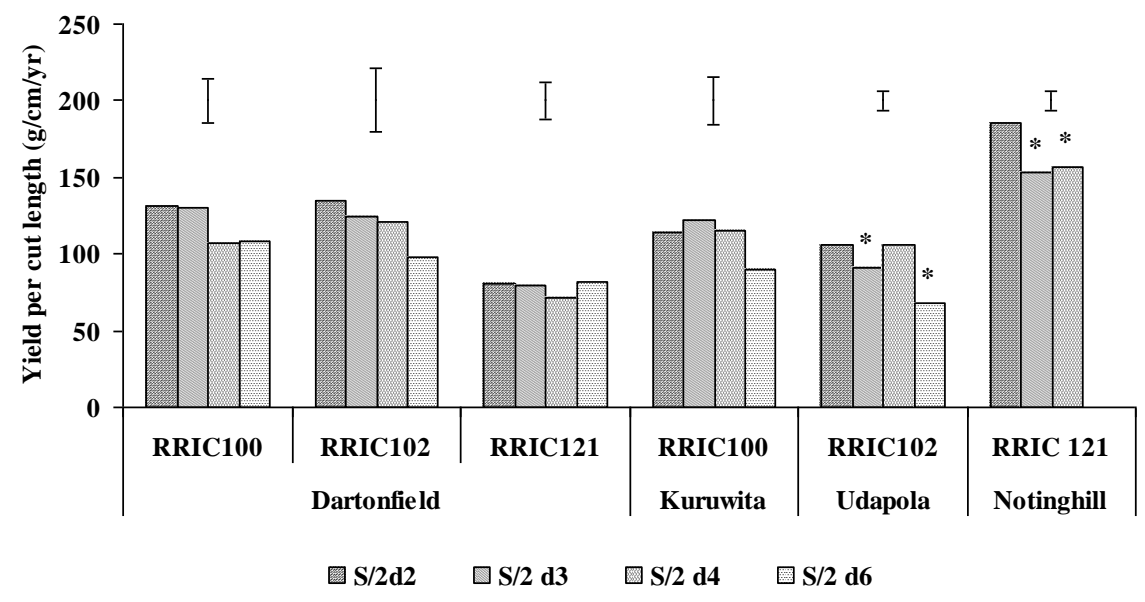

Fig. 3. Yield per unit length of tapping cut (YPCL) in different Low Frequency Harvesting $(\mathrm{LFH})$ systems. Error bars indicate the minimum significant difference for the location and the symbol ' $*$ ' is to show the significant difference $(p<0.05)$ of the respective mean value from the mean of $\mathrm{S} / 2 \mathrm{~d} 2$ system

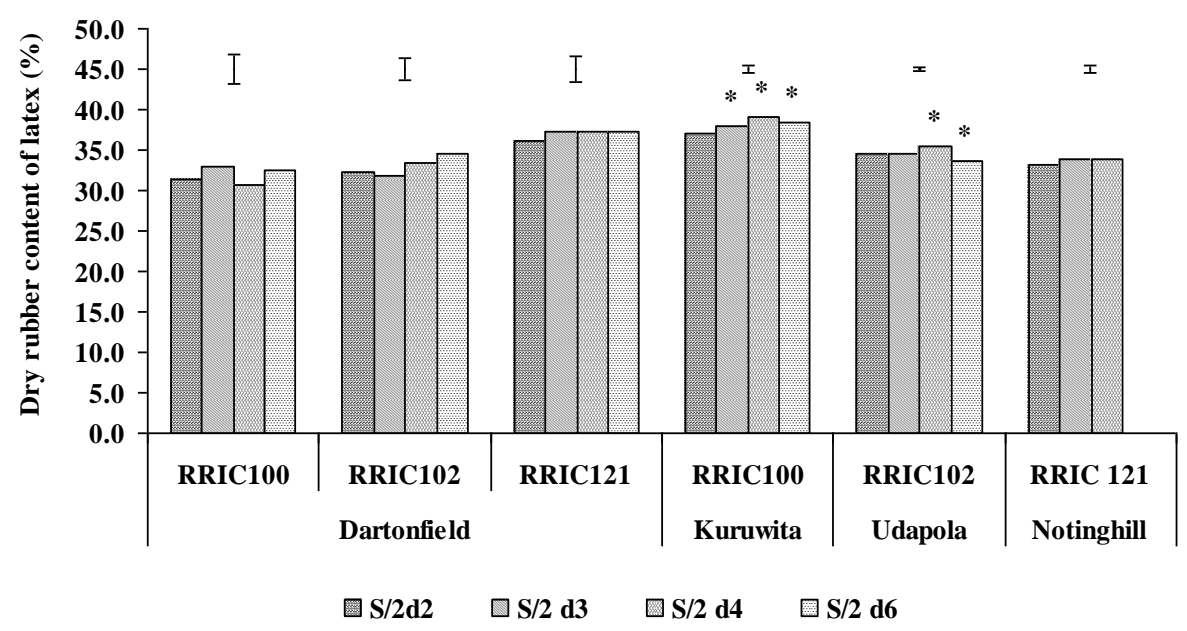

Fig. 4. Percentage dry rubber content in latex $(\% \mathrm{DRC})$ in different Low Frequency Harvesting (LFH) systems. Error bars indicate the minimum significant difference for the location and the symbol ' $*$ ' is to show the significant difference $(\mathrm{p}<0.05)$ of the respective mean value from the mean of $\mathrm{S} / 2 \mathrm{~d} 2$ system 
V H L Rodrigo et al.

Bark consumption per tapping was slightly higher in LFH systems than in traditional $\mathrm{S} / 2 \mathrm{~d} 2$ system except in Notinghill estate where it was alike in all tapping systems with the lowest values recorded (Table 2). Nevertheless as shown by annual bark consumption, overall bark usage was less in LFH systems. Therefore, in all locations except in Udapola estate, expected duration of harvesting in base panels of $\mathrm{S} / 2 \mathrm{~d} 4$ and $\mathrm{S} / 2$ d6 systems showed considerable increase over that of traditional $\mathrm{S} / 2 \mathrm{~d} 2$ with $25 \%, 50 \%$ and $95 \%$ increase in $\mathrm{S} / 2 \mathrm{~d} 3, \mathrm{~S} / 2 \mathrm{~d} 4$ and $\mathrm{S} / 2$ d6 systems, respectively. Trees affected with Tapping Panel Dryness (TPD) were below $10 \%$ in most of tapping systems in different localities (Table 3). In Kuruwita, TPD was $12.5 \%$ in traditional $\mathrm{S} / 2 \mathrm{~d} 2$ system whilst it was significantly less in all three LFH systems. In Udapola, irrespective of the tapping systems, TPD was higher whilst the lowest values were recorded in Notinghill estate (Table 3). In general, tree growth with respect to annual rate of girth increase and bark thickness has not been affected by any LFH system with the respective average values of $1.31 \mathrm{~cm}$ and $1.4 \mathrm{~mm}$ per year. Nevertheless, trees in Notinghill showed higher rate of girth increment irrespective of the tapping system (Table 4).

Laboratory analyses of latex in Dartonfield estate showed that there was a tendency in increasing the percentage dry rubber content (\%DRC) and total solid content (\%TSC) with the decrease in tapping frequency (Table 5). Except in RRIC 100, \%DRC in S/2 d4 and S/2 d6 systems were significantly greater than that of $S / 2 d 2$. Irrespective of the clone, \% TSC was significantly higher in $\mathrm{S} / 2 \mathrm{~d} 4$ and $\mathrm{S} / 2 \mathrm{~d} 6$ than in $\mathrm{S} / 2 \mathrm{~d} 2$. Percentage acetone extractable nonrubber (\%AENR) did not vary significantly from $\mathrm{S} / 2 \mathrm{~d} 2$ with the reduction in tapping frequency with the mean value of $2.24 \%$ for all clones. Only in RRIC 121, significantly less $\%$ AENR was recorded in $\mathrm{S} / 2 \mathrm{~d} 6$ when compared with the values of $\mathrm{S} / 2 \mathrm{~d} 2$ and $\mathrm{S} / 2 \mathrm{~d} 3$.

Sucrose levels tended to decline with the decrease in tapping frequency irrespective of the clone; however, differences were statistically significant only in RRIC 102 (Fig.5). When compared with the values in other clones, the sucrose level in clone RRIC121 was rather low, particularly in $\mathrm{S} / 2 \mathrm{~d} 2$ and $\mathrm{S} / 2 \mathrm{~d} 3$ systems. Inorganic phosphorous $(\mathrm{Pi})$ in latex remained more or less same among the tapping systems and clones. Similarly, thiol also did not vary among tapping systems. Harvesting systems had no influence on $\mathrm{pH}$ of latex in RRIC 100 and RRIC 121 clones (Table 6). However in RRIC 102 , significantly lower latex $\mathrm{pH}$ values were observed in $S / 2 \mathrm{~d} 3$ and $S / 2$ d6 system. When compared with RRIC 100 and RRIC 102, pH values were found to slightly low in RRIC 121. 
Harvesting rubber once in four days

Table 2. Bark consumption of different tapping systems in different locations

\begin{tabular}{|c|c|c|c|c|c|}
\hline \multirow{2}{*}{$\begin{array}{l}\text { Location } \\
\text { (Clone) }\end{array}$} & \multirow{2}{*}{$\begin{array}{l}\text { Tapping } \\
\text { system }\end{array}$} & \multicolumn{2}{|c|}{ Bark consumption } & \multicolumn{2}{|c|}{$\begin{array}{l}\text { Virgin \& renewed panels } \\
\text { harvesting }\end{array}$} \\
\hline & & $\begin{array}{l}\text { Annual } \\
\text { (cm) }\end{array}$ & $\begin{array}{c}\text { per tapping } \\
(\mathrm{cm})\end{array}$ & $\begin{array}{l}\text { Expected } \\
\text { years }\end{array}$ & $\begin{array}{c}\% \text { increase over d2 } \\
\text { harvesting }\end{array}$ \\
\hline \multirow{4}{*}{$\begin{array}{l}\text { Dartonfield } \\
\text { RRIC } 100\end{array}$} & $\mathrm{~S} / 2 \mathrm{~d} 2$ & 31.72 & 0.198 & 15.14 & - \\
\hline & $\mathrm{S} / 2 \mathrm{~d} 3$ & 23.49 & 0.222 & 20.44 & 35.01 \\
\hline & $\mathrm{S} / 2 \mathrm{~d} 4$ & 18.33 & 0.218 & 26.18 & 72.92 \\
\hline & $\mathrm{S} / 2 \mathrm{~d} 6$ & 14.09 & 0.271 & 34.06 & 124.96 \\
\hline \multirow{4}{*}{$\begin{array}{l}\text { Dartonfield } \\
\text { RRIC } 102\end{array}$} & $\mathrm{~S} / 2 \mathrm{~d} 2$ & 33.08 & 0.209 & 14.52 & - \\
\hline & $\mathrm{S} / 2 \mathrm{~d} 3$ & 23.67 & 0.213 & 20.28 & 39.67 \\
\hline & $\mathrm{S} / 2 \mathrm{~d} 4$ & 18.96 & 0.226 & 25.32 & 78.92 \\
\hline & $\mathrm{S} / 2 \mathrm{~d} 6$ & 15.01 & 0.263 & 31.98 & 120.25 \\
\hline \multirow{4}{*}{$\begin{array}{l}\text { Dartonfield } \\
\text { RRIC } 121\end{array}$} & $\mathrm{~S} / 2 \mathrm{~d} 2$ & 33.22 & 0.214 & 14.44 & - \\
\hline & $\mathrm{S} / 2 \mathrm{~d} 3$ & 22.87 & 0.218 & 20.98 & 45.29 \\
\hline & $\mathrm{S} / 2 \mathrm{~d} 4$ & 19.94 & 0.252 & 24.08 & 66.76 \\
\hline & $\mathrm{S} / 2 \mathrm{~d} 6$ & 14.89 & 0.281 & 32.24 & 123.27 \\
\hline \multirow{4}{*}{$\begin{array}{l}\text { Kuruwita } \\
\text { RRIC 100 }\end{array}$} & $\mathrm{S} / 2 \mathrm{~d} 2$ & 24.21 & 0.149 & 19.82 & - \\
\hline & $\mathrm{S} / 2 \mathrm{~d} 3$ & 19.03 & 0.175 & 25.24 & 27.35 \\
\hline & $\mathrm{S} / 2 \mathrm{~d} 4$ & 15.60 & 0.184 & 30.76 & 55.20 \\
\hline & $\mathrm{S} / 2 \mathrm{~d} 6$ & 12.38 & 0.229 & 38.78 & 95.66 \\
\hline \multirow{4}{*}{$\begin{array}{l}\text { Udapola } \\
\text { RRIC } 102\end{array}$} & $\mathrm{~S} / 2 \mathrm{~d} 2$ & 36.99 & 0.215 & 12.96 & - \\
\hline & $\mathrm{S} / 2 \mathrm{~d} 3$ & 30.98 & 0.274 & 15.50 & 19.60 \\
\hline & $\mathrm{S} / 2 \mathrm{~d} 4$ & 30.65 & 0.361 & 15.66 & 17.24 \\
\hline & $\mathrm{S} / 2 \mathrm{~d} 6$ & 25.76 & 0.460 & 18.64 & 43.83 \\
\hline \multirow{3}{*}{$\begin{array}{l}\text { Notinghill } \\
\text { RRIC } 121\end{array}$} & $\mathrm{~S} / 2 \mathrm{~d} 2$ & 24.94 & 0.150 & 19.24 & - \\
\hline & $\mathrm{S} / 2 \mathrm{~d} 3$ & 15.84 & 0.140 & 30.30 & 57.48 \\
\hline & $\mathrm{S} / 2 \mathrm{~d} 4$ & 13.32 & 0.150 & 36.04 & 87.32 \\
\hline
\end{tabular}


V H L Rodrigo et al.

Table 3. Trees affected with Tapping Panel Dryness (TPD) in different tapping system at different locations. The symbol '*' is to show the significant difference $(p<0.05)$ of the respective value from that of $\mathrm{S} / 2 \mathrm{~d} 2$ system

\begin{tabular}{|c|c|c|}
\hline $\begin{array}{l}\text { Location } \\
\text { (Clone) }\end{array}$ & $\begin{array}{c}\text { Tapping } \\
\text { system }\end{array}$ & $\begin{array}{l}\% \text { trees } \\
\text { affected }\end{array}$ \\
\hline \multirow{4}{*}{$\begin{array}{l}\text { Dartonfield } \\
\text { RRIC } 100\end{array}$} & $\mathrm{~S} / 2 \mathrm{~d} 2$ & 5.7 \\
\hline & $\mathrm{S} / 2 \mathrm{~d} 3$ & 8.2 \\
\hline & $\mathrm{S} / 2 \mathrm{~d} 4$ & 5.3 \\
\hline & $\mathrm{S} / 2 \mathrm{~d} 6$ & 4.2 \\
\hline \multirow{4}{*}{$\begin{array}{l}\text { Dartonfield } \\
\text { RRIC } 102\end{array}$} & $\mathrm{~S} / 2 \mathrm{~d} 2$ & 2.8 \\
\hline & $\mathrm{S} / 2 \mathrm{~d} 3$ & 8.2 \\
\hline & $\mathrm{S} / 2 \mathrm{~d} 4$ & 4.1 \\
\hline & $\mathrm{S} / 2 \mathrm{~d} 6$ & 5.4 \\
\hline \multirow{4}{*}{$\begin{array}{l}\text { Dartonfield } \\
\text { RRIC 121 }\end{array}$} & $\mathrm{S} / 2 \mathrm{~d} 2$ & 4.3 \\
\hline & $\mathrm{S} / 2 \mathrm{~d} 3$ & 2.7 \\
\hline & $\mathrm{S} / 2 \mathrm{~d} 4$ & 8.2 \\
\hline & $\mathrm{S} / 2 \mathrm{~d} 6$ & 9.3 \\
\hline \multirow{4}{*}{$\begin{array}{l}\text { Kuruwita } \\
\text { RRIC } 100\end{array}$} & $\mathrm{~S} / 2 \mathrm{~d} 2$ & 12.5 \\
\hline & $\mathrm{S} / 2 \mathrm{~d} 3$ & $4.1 *$ \\
\hline & $\mathrm{S} / 2 \mathrm{~d} 4$ & $8.8^{*}$ \\
\hline & $\mathrm{S} / 2 \mathrm{~d} 6$ & $4.1 *$ \\
\hline \multirow{4}{*}{$\begin{array}{l}\text { Udapola } \\
\text { RRIC } 102\end{array}$} & $\mathrm{~S} / 2 \mathrm{~d} 2$ & 10.7 \\
\hline & $\mathrm{S} / 2 \mathrm{~d} 3$ & 9.3 \\
\hline & $\mathrm{S} / 2 \mathrm{~d} 4$ & 13.3 \\
\hline & $\mathrm{S} / 2 \mathrm{~d} 6$ & 12.0 \\
\hline \multirow{3}{*}{$\begin{array}{l}\text { Notinghill } \\
\text { RRIC } 121\end{array}$} & $\mathrm{~S} / 2 \mathrm{~d} 2$ & - \\
\hline & $\mathrm{S} / 2 \mathrm{~d} 3$ & 2.7 \\
\hline & $\mathrm{S} / 2 \mathrm{~d} 4$ & 4.0 \\
\hline
\end{tabular}

In short-term testing on Ethephon concentration, the estimated YPT of S/2 d4 was found to increase with the increase in Ethephon concentration (Fig. 6). The response of YPT to low level of Ethephon concentrations was poor in Notinghill of the Intermediate zone, however at higher levels, the response was more or less same with that in the wet zone. According to the trend lines fitted and the YPT of traditional S/2 d2 system, the suitable Ethephon concentrations to $\mathrm{S} / 2 \mathrm{~d} 4$ in Wet and Intermediate zones were $3.23 \%$ and $3.79 \%$, respectively.

Commercial testing of $\mathrm{S} / 2 \mathrm{~d} 4$ in Udapola estate showed no reduction in yields in terms of YPT and YPH. Instead, they appreciated little by $c a$. $7 \%$ when compared with the yields of $\mathrm{S} / 2$ d3 system (Table 7). Similar response was shown by $\mathrm{S} / 2 \mathrm{~d} 4$ in Kuruwita substation over the $\mathrm{S} / 2 \mathrm{~d} 2$ system. However, yields given by $\mathrm{S} / 2$ $\mathrm{d} 4$ in Notinghill was only about $81 \%$ of that produced by $\mathrm{S} / 2 \mathrm{~d} 2$. In this estate, $\mathrm{S} / 2$ d3 system was also capable of providing only $93 \%$ of the yield given by $\mathrm{S} / 2 \mathrm{~d} 2$. In all locations, intake per harvester (IPH) was greater in $\mathrm{S} / 2 \mathrm{~d} 4$ system when compared to the other systems tested. In Udapola, IPH was $44 \%$ higher in $\mathrm{S} / 2 \mathrm{~d} 4$ over the value of S/2 d3 and in Notinghill and Kuruwita, increase in IPH was $61 \%$ and $113 \%$ over the values of $S / 2 \mathrm{~d} 2$, respectively. In Notinghill, \%DRC in all tapping systems was $c a$. 30\% whilst it was above $35 \%$ in other two estates in any tapping system (Table 7). 
(a)

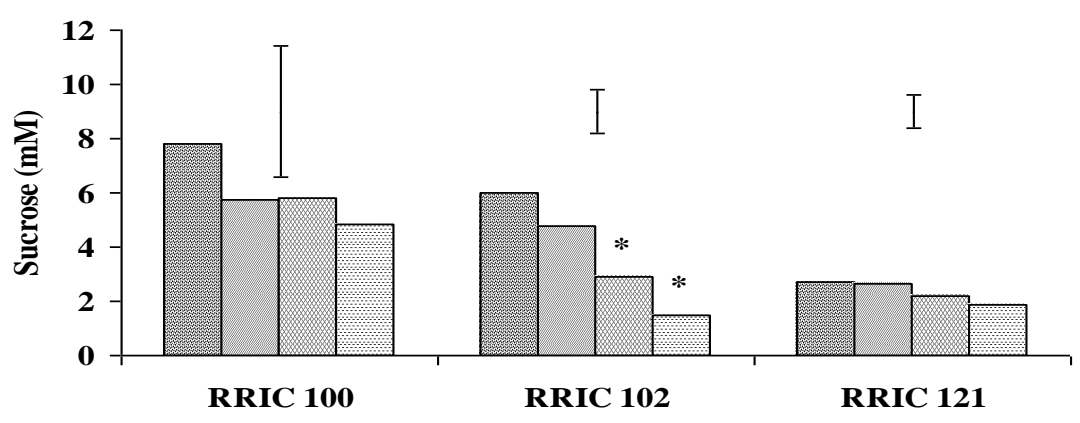

(b)

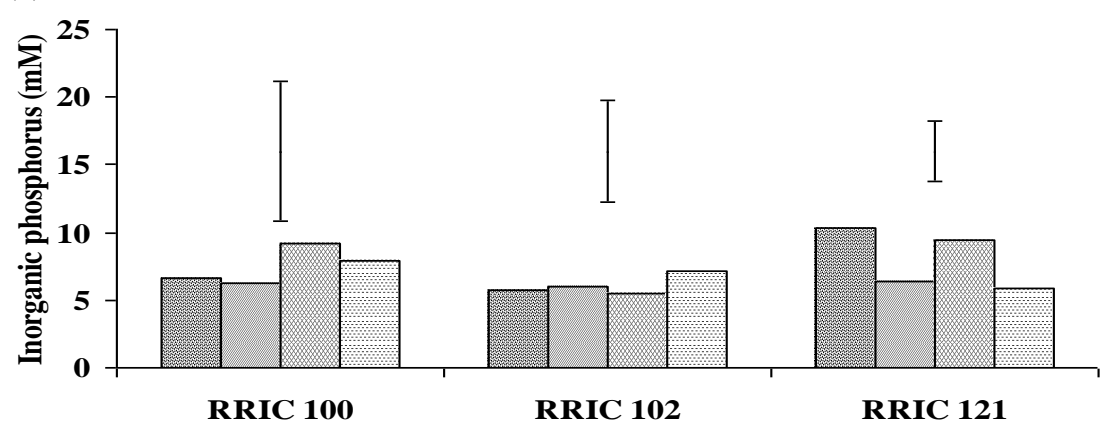

(c)

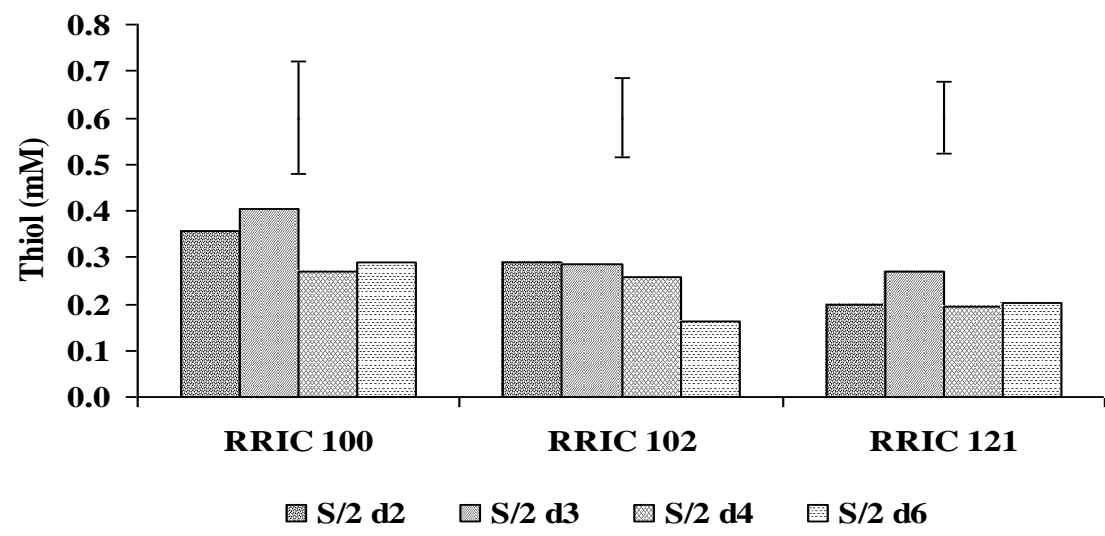

Fig. 5. Variation in latex physiological parameters among the low frequency harvesting systems tested: In (a) Sucrose (b) Thiol and (c) Inorganic phosphorus of latex. Error bars indicate the minimum significant difference for the location and the symbol ' $*$ ' is to show the significant difference $(\mathrm{p}<0.05)$ of the respective mean value from the mean of $\mathrm{S} / 2 \mathrm{~d} 2$ system 
(a)

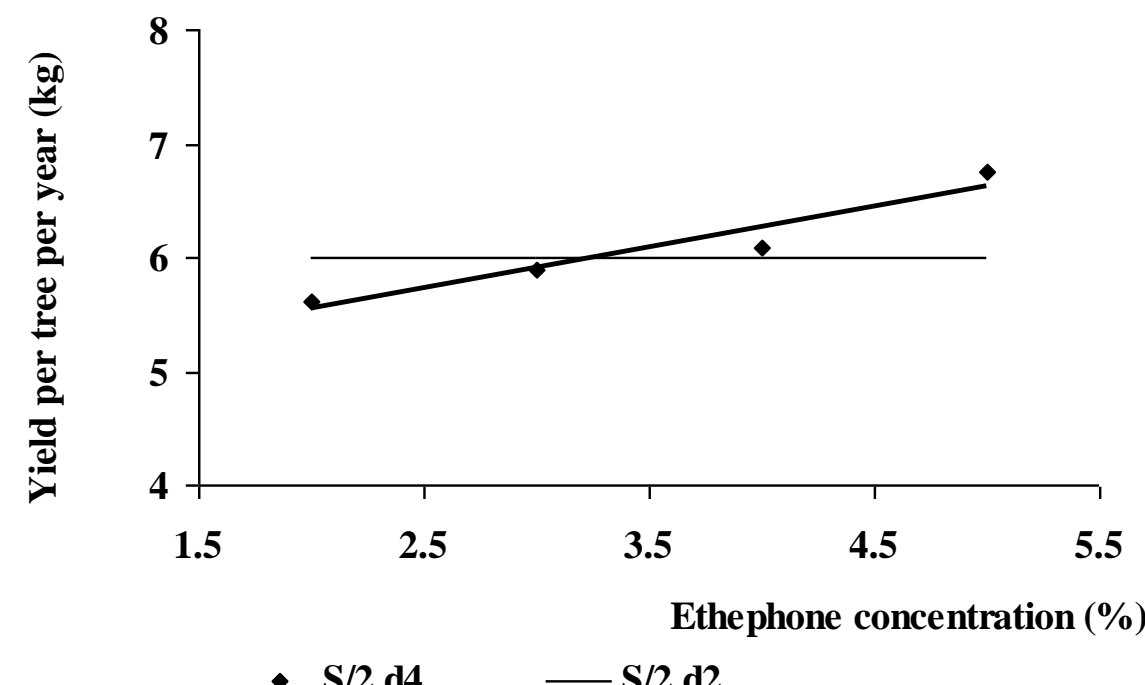

- $\mathrm{S} / 2 \mathrm{~d} 4+\mathrm{S} / 2 \mathrm{~d} 2$

(b)

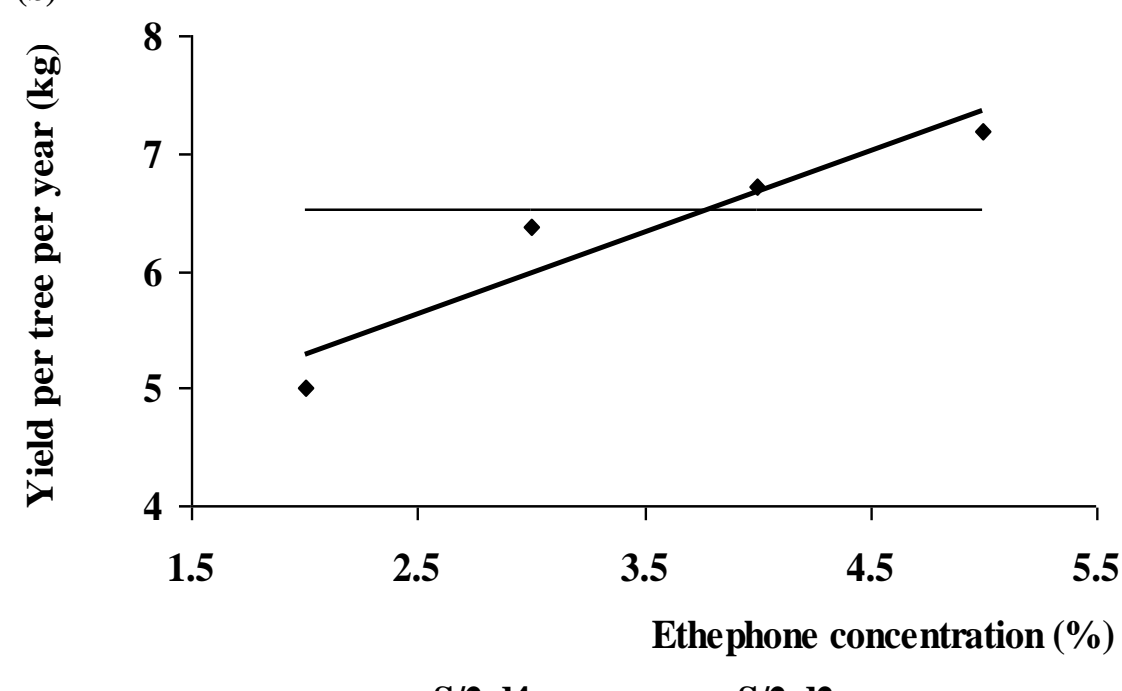

- S/2 d4 $-\mathrm{S} / 2 \mathrm{~d} 2$

Fig. 6. Response of $\mathrm{S} / 2 \mathrm{~d} 4$ to different Ethephon concentrations in (a) Wet and (b) Intermediate zones. The yield given by the traditional $\mathrm{S} / 2 \mathrm{~d} 2$ (without stimulation) is illustrated as a horizontal line 
Harvesting rubber once in four days

Table 4. Growth parameters of different tapping systems at different locations

\begin{tabular}{|c|c|c|c|c|c|}
\hline $\begin{array}{l}\text { Location } \\
\text { (Clone) }\end{array}$ & $\begin{array}{l}\text { Tapping } \\
\text { system }\end{array}$ & $\begin{array}{l}\text { Initial } \\
\text { girth } \\
(\mathbf{c m})\end{array}$ & $\begin{array}{c}\text { Girth } \\
\text { increment } \\
(\mathrm{cm} / \mathrm{yr} .)\end{array}$ & $\begin{array}{l}\text { Initial bark } \\
\text { thickness } \\
(\mathrm{mm})\end{array}$ & $\begin{array}{c}\text { Bark thickness } \\
\text { increment } \\
(\mathrm{mm} / \mathrm{yr} .)\end{array}$ \\
\hline Dartonfield & $\mathrm{S} / 2 \mathrm{~d} 2$ & 72.99 & 1.21 & 9 & 2 \\
\hline \multirow[t]{3}{*}{ RRIC 100} & $\mathrm{~S} / 2 \mathrm{~d} 3$ & 72.25 & 1.11 & 8 & 2 \\
\hline & $\mathrm{S} / 2 \mathrm{~d} 4$ & 72.69 & 1.18 & 8 & 2 \\
\hline & $\mathrm{S} / 2 \mathrm{~d} 6$ & 74.31 & 1.20 & 9 & 2 \\
\hline \multirow{4}{*}{$\begin{array}{l}\text { Dartonfield } \\
\text { RRIC } 102\end{array}$} & $\mathrm{~S} / 2 \mathrm{~d} 2$ & 71.96 & 1.34 & 9 & 1 \\
\hline & $\mathrm{S} / 2 \mathrm{~d} 3$ & 70.23 & 1.16 & 8 & 1 \\
\hline & $\mathrm{S} / 2 \mathrm{~d} 4$ & 71.26 & 1.07 & 7 & 2 \\
\hline & $\mathrm{S} / 2 \mathrm{~d} 6$ & 71.54 & 1.13 & 7 & 2 \\
\hline Dartonfield & $\mathrm{S} / 2 \mathrm{~d} 2$ & 65.65 & 1.02 & 6 & 1 \\
\hline \multirow[t]{3}{*}{ RRIC 121} & $\mathrm{~S} / 2 \mathrm{~d} 3$ & 65.93 & 0.95 & 7 & 1 \\
\hline & $\mathrm{S} / 2 \mathrm{~d} 4$ & 66.58 & 0.94 & 6 & 2 \\
\hline & $S / 2 d 6$ & 68.04 & 1.07 & 7 & 1 \\
\hline Kuruwita & $\mathrm{S} / 2 \mathrm{~d} 2$ & 67.34 & 1.39 & 10 & 2 \\
\hline \multirow[t]{3}{*}{ RRIC 100} & $\mathrm{~S} / 2 \mathrm{~d} 3$ & 67.99 & 1.50 & 10 & 1 \\
\hline & $\mathrm{S} / 2 \mathrm{~d} 4$ & 67.90 & 1.56 & 11 & 1 \\
\hline & $\mathrm{S} / 2 \mathrm{~d} 6$ & 67.91 & 1.54 & 10 & 1 \\
\hline Udapola & $\mathrm{S} / 2 \mathrm{~d} 2$ & 65.49 & 1.37 & 8 & 1 \\
\hline \multirow[t]{3}{*}{ RRIC 102} & $\mathrm{~S} / 2 \mathrm{~d} 3$ & 66.37 & 1.15 & 8 & 1 \\
\hline & $\mathrm{S} / 2 \mathrm{~d} 4$ & 66.20 & 1.15 & 8 & 1 \\
\hline & $\mathrm{S} / 2 \mathrm{~d} 6$ & 64.41 & 1.13 & 8 & 2 \\
\hline Notinghill & $\mathrm{S} / 2 \mathrm{~d} 2$ & 63.88 & 2.02 & 6 & 1 \\
\hline \multirow[t]{2}{*}{ RRIC 121} & $\mathrm{~S} / 2 \mathrm{~d} 3$ & 65.78 & 2.08 & 6 & 1 \\
\hline & $\mathrm{S} / 2 \mathrm{~d} 4$ & 62.03 & 1.90 & 6 & 1 \\
\hline
\end{tabular}

Summary of the financial analyses made on $\mathrm{S} / 2$ d4 system in different locations is given in Table 8 . The highest profit of $\mathrm{S} / 2 \mathrm{~d} 4$ was recorded in Kuruwita substation and in both Kuruwita and Udapola, it was more profitable than the standard tapping systems of S/2 d2 and $\mathrm{S} / 2 \mathrm{~d} 3$. Additional profit gained in Kuruwita was Rs.137,494/= per hectare per annum whilst it was Rs.78,594/= in Udapola. In Notinghill, there was a loss of Rs.173,294/= per hectare per annum with the application of $\mathrm{S} / 2 \mathrm{~d} 4$. In all sites, tapping cost and overall cost of production were reduced by $\mathrm{S} / 2 \mathrm{~d} 4$ although there was additional cost involved in Ethephon stimulation. The highest cost for the stimulation was recorded as Rs.6.13 (for both labour and chemical) in Notinghill and overall reduction in cost of production was Rs.28.52 for Kuruwita and Udapola sites. Further, harvesters' income per day was increased by Rs.141/= in Kuruwita, Rs.60/= in Udapola and Rs.90/= in Notinghill by S/2 d4 tapping system (Table 8 ). 
Table 5. Latex properties of different harvesting systems in Dartonfield estate. Means with same letter are not significantly different at each location. Codes DRC, TSC and AENR refer to percentage dry rubber, total solid content and acetone extractable non-rubber in latex

\begin{tabular}{lcccc}
\hline Clone & $\begin{array}{c}\text { Tapping } \\
\text { system }\end{array}$ & $\begin{array}{c}\text { DRC } \\
(\%)\end{array}$ & $\begin{array}{c}\text { TSC } \\
(\% \mathbf{w} / \mathbf{})\end{array}$ & $\begin{array}{c}\text { AENR } \\
\text { (\%w/w) }\end{array}$ \\
\hline RRIC 100 & $\mathrm{S} / 2 \mathrm{~d} 2$ & $37.12 \mathrm{~b}$ & $39.73 \mathrm{c}$ & $2.53 \mathrm{a}$ \\
& $\mathrm{S} / 2 \mathrm{~d} 3$ & $39.37 \mathrm{ab}$ & $41.91 \mathrm{~b}$ & $2.34 \mathrm{a}$ \\
& $\mathrm{S} / 2 \mathrm{~d} 4$ & $38.85 \mathrm{~b}$ & $41.74 \mathrm{~b}$ & $2.23 \mathrm{a}$ \\
& $\mathrm{S} / 2 \mathrm{~d} 6$ & $41.51 \mathrm{a}$ & $43.44 \mathrm{a}$ & $2.43 \mathrm{a}$ \\
\hline RRIC 102 & $\mathrm{S} / 2 \mathrm{~d} 2$ & $38.04 \mathrm{c}$ & $40.72 \mathrm{c}$ & $2.30 \mathrm{a}$ \\
& $\mathrm{S} / 2 \mathrm{~d} 3$ & $38.83 \mathrm{c}$ & $41.55 \mathrm{c}$ & $2.32 \mathrm{a}$ \\
& $\mathrm{S} / 2 \mathrm{~d} 4$ & $40.63 \mathrm{~b}$ & $43.59 \mathrm{~b}$ & $2.18 \mathrm{a}$ \\
& $\mathrm{S} / 2 \mathrm{~d} 6$ & $42.42 \mathrm{a}$ & $44.83 \mathrm{a}$ & $2.21 \mathrm{a}$ \\
\hline RRIC 121 & $\mathrm{S} / 2 \mathrm{~d} 2$ & $34.49 \mathrm{c}$ & $36.99 \mathrm{c}$ & $2.26 \mathrm{a}$ \\
& $\mathrm{S} / 2 \mathrm{~d} 3$ & $36.04 \mathrm{bc}$ & $38.22 \mathrm{bc}$ & $2.20 \mathrm{a}$ \\
& $\mathrm{S} / 2 \mathrm{~d} 4$ & $37.92 \mathrm{ab}$ & $40.25 \mathrm{~b}$ & $1.98 \mathrm{ab}$ \\
& $\mathrm{S} / 2 \mathrm{~d} 6$ & $40.08 \mathrm{a}$ & $42.66 \mathrm{a}$ & $1.90 \mathrm{~b}$ \\
\hline
\end{tabular}

Table 6. Variation of $p H$ in latex harvested under different harvesting systems in Dartonfield estate

\begin{tabular}{llll}
\hline Clone & $\begin{array}{l}\text { Tapping } \\
\text { system }\end{array}$ & Latex pH & Average \\
\hline RRIC 100 & $\mathrm{S} / 2 \mathrm{~d} 2$ & $7.01-7.17$ & 7.09 \\
& $\mathrm{~S} / 2 \mathrm{~d} 3$ & $7.11-7.26$ & 7.19 \\
& $\mathrm{~S} / 2 \mathrm{~d} 4$ & $7.13-7.26$ & 7.20 \\
& $\mathrm{~S} / 2 \mathrm{~d} 6$ & $7.10-7.20$ & 7.15 \\
\hline RRIC 102 & $\mathrm{S} / 2 \mathrm{~d} 2$ & $7.15-7.52$ & 7.34 \\
& $\mathrm{~S} / 2 \mathrm{~d} 3$ & $6.74-6.90$ & $6.82^{*}$ \\
& $\mathrm{~S} / 2 \mathrm{~d} 4$ & $7.08-7.17$ & 7.13 \\
& $\mathrm{~S} / 2 \mathrm{~d} 6$ & $6.95-7.05$ & $7.00^{*}$ \\
\hline RRIC 121 & $\mathrm{S} / 2 \mathrm{~d} 2$ & $6.70-6.82$ & 6.76 \\
& $\mathrm{~S} / 2 \mathrm{~d} 3$ & $6.50-6.88$ & 6.69 \\
& $\mathrm{~S} / 2 \mathrm{~d} 4$ & $6.44-6.86$ & 6.65 \\
& $\mathrm{~S} / 2 \mathrm{~d} 6$ & $6.28-7.12$ & 6.70 \\
\hline
\end{tabular}


Table 7. Yield parameters in commercial scale testing of low frequency harvesting systems. Codes \%DRC, IPH, YPT and YPH refer to percentage dry rubber content in latex, Intake per harvester per day, yield per tree per year and yield per hectare per year, respectively

\begin{tabular}{lllrlll}
\hline Clone & $\begin{array}{l}\text { Tapping } \\
\text { system }\end{array}$ & $\begin{array}{l}\text { DRC } \\
(\boldsymbol{\%})\end{array}$ & $\begin{array}{l}\text { IPH } \\
(\mathbf{k g})\end{array}$ & $\begin{array}{l}\text { YPT } \\
(\mathbf{k g})\end{array}$ & $\begin{array}{l}\text { YPH } \\
(\mathbf{k g})\end{array}$ & $\begin{array}{l}\text { \% yield } \\
\text { increased over } \\
\text { S/2 d2 }\end{array}$ \\
\hline Nottinghill & $\mathrm{S} / 2 \mathrm{~d} 2$ & 30.14 & 9.8 & 5.85 & 2340 & - \\
RRIC 121 & $\mathrm{S} / 2 \mathrm{~d} 3$ & 30.57 & 13.5 & 5.45 & 2179 & 93.1 \\
& $\mathrm{~S} / 2 \mathrm{~d} 4$ & 30.44 & 15.8 & 4.73 & 1893 & 80.9 \\
\hline Kuruwita & $\mathrm{S} / 2 \mathrm{~d} 2$ & 36.34 & 8.3 & 4.97 & 1988 & - \\
RRIC 100 & $\mathrm{S} / 2 \mathrm{~d} 4$ & 36.11 & 17.7 & 5.30 & 2120 & 106.6 \\
\hline Udapola & $\mathrm{S} / 2 \mathrm{~d} 3$ & 37.51 & 9.1 & 3.70 & 1471 & - \\
RRIC 121 & $\mathrm{S} / 2 \mathrm{~d} 4$ & 35.92 & 13.1 & 3.90 & 1567 & 106.5 \\
\hline
\end{tabular}

Table 8. Summary of the financial analyses made on $S / 2 d 4$ system at commercial scale in different locations

\begin{tabular}{|c|c|c|c|c|c|c|}
\hline \multirow[t]{2}{*}{ Harvesting system } & \multicolumn{2}{|c|}{ Udapola } & \multicolumn{2}{|c|}{ Kuruwita } & \multicolumn{2}{|c|}{ Notinghill } \\
\hline & $\mathrm{S} / 2 \mathrm{~d} 3$ & $\mathrm{~S} / 2 \mathrm{~d} 4$ & $\mathrm{~S} / 2 \mathrm{~d} 2$ & $\mathrm{~S} / 2 \mathrm{~d} 4$ & $\mathrm{~S} / 2 \mathrm{~d} 2$ & $\mathrm{~S} / 2 \mathrm{~d} 4$ \\
\hline $\begin{array}{l}\text { Intake per harvester } \\
(\mathrm{kg})\end{array}$ & 9 & 13 & 8 & 18 & 10 & 16 \\
\hline $\begin{array}{l}\text { Harvester's income } \\
\text { (Rs./day) }\end{array}$ & 602 & 662 & 587 & 737 & 617 & 707 \\
\hline $\begin{array}{l}\text { Tapping cost with } \\
\text { stimulation } \\
\text { (Rs./kg) }\end{array}$ & 69.09 & 55.39 & 71.27 & 46.86 & 62.65 & 50.69 \\
\hline $\begin{array}{l}\text { Cost of stimulation } \\
\text { (Rs./kg) } \\
\text { (for chemicals) }\end{array}$ & 1.20 & 1.97 & 0.00 & 2.60 & 0.00 & 2.92 \\
\hline $\begin{array}{l}\text { Cost of stimulation } \\
\text { (Rs./kg) } \\
\text { (for labour ) }\end{array}$ & 1.74 & 2.88 & 0.00 & 2.87 & 0.00 & 3.21 \\
\hline COP (Rs./kg) & 175.59 & 153.01 & 177.77 & 143.31 & 169.15 & 182.41 \\
\hline $\begin{array}{l}\text { Profit } \\
\text { Rs./hectare/yr }\end{array}$ & $471,037 /=$ & $549,631 /=$ & $618,691 /=$ & $756,185 /=$ & $774,182 /=$ & $600,888 /=$ \\
\hline
\end{tabular}




\section{Discussion}

Obviously, low frequency harvesting (LFH) systems are capable of reducing the number of workers required for latex harvesting hence address the issue of lack of skill workers in rubber plantations. For instance, $S / 2$ d 3 tapping reduces the requirement of latex harvesters by $1 / 3$. In $S / 2 d 4$, the requirement of harvesters is only $1 / 2$ from that of the traditional system of $\mathrm{S} / 2$ d2. In the absence of suitable mechanized devices for latex harvesting, LFH systems appeared to be the only way to address the labour issues. Further, harvesting represents the largest component of cost of production $(c a .1 / 3)$ and that is mainly for labour hence any reduction in labour use reduces the cost of production of rubber. With the reduction of harvesting frequency, it is expected to have increased yield per each tapping in order to compensate the increased number of untapped days. This demands extra energy to collect the latex and so, incentive pavements are to be offered to the latex harvesters for proper collection of latex. Further, additional cost is involved in the application of stimulants (i.e. chemical and application cost). However, ultimate cost for incentives and stimulant application is expected to be less than the value of reduction in labour resulting in reduced harvesting cost and overall cost of production.

Yield stimulants in rubber had initially been applied to increase the latex yield. In such instances, despite the short term yield increases, there had been subsequent decline in yields. Such yield declines in following years have had a close association with the yields in previous years (Eschbach \& Lacrotte, 1989) indicating the overharvesting/ stress factor in long term. Therefore, yield stimulants should be used carefully only to harvest the potential yield of the tree. Being a time tested system, the yield given by the $\mathrm{S} / 2 \mathrm{~d} 2$ could be considered as the safe level. In this context, yield per tree for a specific period (YPT) (usually for a year) can be used to compare the harvesting systems irrespective of the frequency. In LFH, the increase in yield per tree per tapping (GTT) is expected to be substantial enough to produce the similar amount of YPT that given by the traditional S/2 d2 system.

In the small scale trial on low frequency harvesting (LFH), S/2 d4 system has given a comparable yield to that given by traditional $S / 2 \mathrm{~d} 2$ in all sites of Wet zone (WZ). However, in Notinghill estate of the Intermediate zone (IZ), YPT of $\mathrm{S} / 2 \mathrm{~d} 4$ was significantly less than that given by $S / 2 \mathrm{~d} 2$. Also in the commercial scale trial, similar observation was made. Although the success of $S / 2 d 4$ system in terms of the required yield levels, was evident across the different genotypes and locations in WZ, this suggests that its success in IZ is rather dubious. It is required to test the $\mathrm{S} / 2 \mathrm{~d} 4$ in several sites of IZ before coming to a firm conclusion though it could not be done in the present study as only a few suitable rubber estates were available in this zone for any 
further trials. Not only the $S / 2 d 4$, but also the $\mathrm{S} / 2 \mathrm{~d} 3$ has given less YPT in Notinghill estate supporting the view of less success in LFH in IZ. Similar observation has been made in Ivory Coast where trees tapped once a week with 12 rounds of Ethephon stimulation per year had shown progressive proportional decline in yield with the decrease in annual rainfall when compared with the yield given by unstimulated alternate day harvesting (Eschbach \& Lacrotte, 1989).

Although YPT of S/2 d6 was statistically comparable with that of traditional $\mathrm{S} / 2 \mathrm{~d} 2$ system in the majority of sites, its mean value was apparently less in most occasions except in RRIC 121 in Dartonfield estate. YPT depends mainly on two factors, GTT and number of tapping days per year. The expected number of tapping days has been achieved in $S / 2 d 6$, hence the principal determiner to YPT was GTT. Any short coming in Ethephon application process, tapping and latex collection would have a greater effect on GTT when reducing the tapping frequency and so in this study, the greatest effect should be on $S / 2$ d6. When introducing a new harvesting system to commercial estates, minor mistakes related to such factors are inevitable and therefore, those should be assessed and analyzed carefully before any large scale adoption. Whilst 5\% Ethephon was applied every three tappings at the last stage of this study, experimental evidence in India shows that 5\% Ethephon at monthly intervals is sufficient in $S / 2$ d6 tapping
(Vijayakumar et al., 2004). Genotype used in India (RRII 105) is generally tapped with d3 frequency without stimulation, hence difference in response could be attributed to the difference in genotype.

Although overall bark consumption was reduced significantly with reduced tapping frequency, the rate of its reduction did not exactly proportional with tapping frequency since the shaving thickness (i.e. bark consumption per tapping) increased with the reduction in tapping frequency. There would be an increased length of latex plugged with the reduction of tapping frequency hence a larger slice needs to be removed to have the proper latex flow. However, bark consumption per tapping in $S / 2 d 3$ and $S / 2 d 4$ was comparable in most occasions probably due to less time gap between two systems. The real advantage of reduction in overall bark consumption of LFH is reflected by the increase in expected years for base panel tapping. In most locations, it is expected to have over additional 50\% increase in base panel time period for $\mathrm{S} / 2 \mathrm{~d} 4$ harvesting. Since overall bark consumption is largely reduced by reduction in tapping frequency, such systems delay the commencement of tapping in renewed bark providing additional time period for it to regenerate. Even the virgin bark towards the end of tapping would develop further. With that, higher yield could be expected in the long run in all low intensity systems than what was observed in this study.

According to the latex physiological 
V H L Rodrigo et al.

parameters, stimulation levels associated with all low intensity/frequency harvesting systems have had no adverse effect on tree health. Values recorded for \%DRC in all LFH systems were in the safe level and in most occasions, it was either comparable with or higher than the $\%$ DRC of $\mathrm{S} / 2 \mathrm{~d} 2$. Thiol and inorganic phosphorus in latex were comparable in most occasions among different harvesting systems. Sucrose content tends to decrease with the harvesting frequency and particularly in RRIC 102, it was significantly less in $\mathrm{S} / 2 \mathrm{~d} 4$ and $\mathrm{S} / 2$ d6 systems. That could partly be due to the dilution effect as the total volume of latex per tapping tended to increase with decrease in harvesting frequency as latex samples were collected 30 minutes after tapping and according to literature, sucrose content tends to decline with the increase in latex flow (Coupe and Chrestin, 1989). However, low level of sucrose indicates the difficulty in sustaining the latex synthesis. With no overall yield (YPT) increase, decreased sucrose in low frequency harvesting in RRIC 102 shows temporal increase in demand for sucrose hence depletion in latex synthesis to provide greater GTT.

With comparable yields and reduction in tapping cost, the net income per hectare (overall profits) was very much higher in the newly developed $\mathrm{S} / 2 \mathrm{~d} 4$ than the traditional $\mathrm{S} / 2$ d2 system. Commercial testing in Udapola estate showed that it was even better than $\mathrm{S} / 2$ d3. Despite the positive response in the wet zone, the performance of $\mathrm{S} / 2 \mathrm{~d} 4$ in Notinghill estate in the Intermediate zone was not economically sound although reduction in harvesting cost was prominent. Since additional payment made to harvesters for the latex brought above the norm is less than net value of such latex, harvesting costs are always less in low frequency systems. More importantly, harvesters' income is always higher in any low frequency system with additional latex brought in. At present price of latex (i.e. Rs.500/=), even a marginal decline in overall yield of low frequency harvesting affects the profitability despite of reduction in harvesting cost. That is the situation in $\mathrm{S} / 2 \mathrm{~d} 4$ at Notinghill where yield decline was substantial enough to conceal the benefit of low harvesting cost hence less profit was resulted. Further analyses show that a maximum of $2.7 \%$ decline in yield could be tolerable in $S / 2 d 4$ to obtain the same profit given by $\mathrm{S} / 2 \mathrm{~d} 2$. Even at such yield level, harvesters' income will increase by $28 \%$ showing the benefits of low frequency harvesting. Therefore for the Intermediate zone, stimulation protocol of $\mathrm{S} / 2 \mathrm{~d} 4$ needs to be adjusted to reach the yield given by the traditional system. As the next option, ca. 3.8\% Ethephon could be tried for $\mathrm{S} / 2 \mathrm{~d} 4$ in the Intermediate zone as indicated by short-term experiment. In $\mathrm{S} / 2$ d6 system, the minimum level required is $97.1 \%$ however the level achieved was only $78 \%$ of $\mathrm{S} / 2 \mathrm{~d} 2$. Since the stimulation levels given in $\mathrm{S} / 2 \mathrm{~d} 6$ were 
very high, it is rather sceptical to develop this system further to obtain the required yield level.

Low intensity harvesting systems are yet to be tested under smallholder conditions where farmers work with diverse objectives hence their priority is not always the profit maximization. Even in the large scale plantations, S/2 d3 system is adopted only by few regional plantation companies. Therefore, the next step should be the popularization programme for LFH in the wet zone together with refining the technologies further considering growers' requirements. Also, applicability of these systems to the Intermediate zone is to be tested.

\section{Acknowledgement}

This study was funded by the National Science Foundation under the contract research programme of RG/2006/AG 07 . Research activities were conducted with the valuable assistance of the staff of the Department of Biochemistry and Physiology of Rubber Research Institute of Sri Lanka and the estates of Dartonfield, Rubber Research Institute Sub station, Kuruwita, Udapola estate and Notinghill estate. In particular, technical support given by Mr P D J Rodrigo, Mr R P S Randunu, Mr D S Hewamanage and Ms $\mathrm{H}$ A $\mathrm{M}$ E Hettiarachchi is highly appreciated.

\section{References}

Anon (1984). ISO Standards Hand Book 22, Volume 1 and 2. International Standard Organization.
Anon (1970). Test methods for Standard Malaysian Rubbers. SMR Bulletin (7). Rubber Research Institute of Malaysia.

Boyne, A F and Ellman, G L (1972). A Methodology for analysis of tissue sulphydryl components. Analytical Biochemistry 46, 639-653.

Coupe, M and Chrestin, H (1989). Physicochemical and biochemical mechanisms of hormonal (Ethylene) stimulation. In: Physiology of Rubber Tree Latex. (Eds. J. d' Auzac, J.L. Jacob, H.Chrestin). CRC Press Inc., Florida, USA. pp. 295320.

Eschbach, J M and Lacrotte, R (1989). Factors influencing response to hormonal yield stimulation. In: Physiology of Rubber Tree Latex. (Eds. J. d' Auzac, J. L. Jacob, H. Chrestin). CRC Press Inc. Florida, USA. pp. 321331.

Karunaichamy, K, Vijayakumar, K R, Thomas, K U, Rajgopal, R and Anil Kumar, D (2001). Response of Rubber Trees (Hevea brasilienses Mull. Arg. Clone RRII 105) to Low Frequency Tapping (LFT) Systems. Indian Journal of Natural Rubber Research 14(2), 7989.

Nugawela, A (2001). Use of Yield stimulants and tapping notation. In: Hand Book of Rubber, Agronomy, 191197 (Eds. L. M. K. Tillekeratne and A. Nugawela), Rubber Research Institute of Sri Lanka, Agalawatta, Sri Lanka.

Nugawela, A, Peries, M R C, Wijesekara, S and Samarasekara, R (2000). Evaluation of $d / 3$ tapping with stimulation to alleviate problems related to $\mathrm{d} / 2$ tapping of Hevea. Journal of the Rubber Research Institute of Sri Lanka 83, 4961.

Rodrigo, V H L (2009). Exploitation methods to sustain high performance 
under changing scenarios. Proceedings of the Centennial Rubber Conference, Rubber Research Institute of Sri Lanka, 12-13 May 2009, Colombo, Sri Lanka. P. 29-31.

Rodrigo, V H L, Wickramarathna, N A A D and Vidanapathirana, R D (2004). Productivity and tapper shortage in rubber plantations: how low frequency tapping can address the shortage of tappers in rubber plantations of Sri Lanka. Proceedings of the First Symposium on Plantation Crop Research, July 8-9, 2004, Colombo, Sri Lanka. pp. 32-42.

Scott, T A and Melvin, E H (1953). Analytical Chemistry 25, 1656.

Taussky, H H and Shorr, E (1953). A micro-colourimetric method for the determination of inorganic phosphorous. Journal of Biological Chemistry 202, 675-685.

Vijayakumar, $\mathrm{K}$ R, Thomas, $\mathrm{K}$ U, Rajagopal, $\mathrm{R}$ and Karunaichamy, $\mathrm{K}$
(2004). Successful extension of low frequency tapping in different agroclimates and report on high yield under $1 / 2 \mathrm{~S} \quad \mathrm{D} / 6 \quad 6 \mathrm{D} / 7$ tapping. Proceeding of International Rubber Research and Development Board Conference, 7-8 September 2004, Kunming, China. Pp 12.

Xuehua, L U O, Yunqing, L I U, Xiujuan, C A I, Juqun, $\mathrm{W} \mathrm{U}$ and Bixia, $\mathrm{Z} \mathrm{H} \mathrm{O} \mathrm{U}$ (2004). Effect of different tapping systems on the mineral nutrient of latex total solids of RRIM 600 tree. Proceeding of International Rubber Research and Development Board Conference, 7-8 September 2004, Kunming, China. Pp 8.

Address for correspondence: Dr V H L Rodrigo, Head, Biochemistry \& Physiology Dept., Rubber Research Institute of Sri Lanka, Dartonfield, Agalawatta, Sri Lanka. E-mail: laksh@sltnet.lk 